\title{
A INTERNACIONAL COMUNISTA E A QUESTÃO JUDAICA
}

\section{THE COMMUNIST INTERNATIONAL AND THE JEWISH QUESTION}

\author{
Saul Kirschbaum*
}

\begin{abstract}
Resumo: O relacionamento dos judeus com o poder na Rússia nos quatro séculos desde o tsarado de Ivã IV, o Terrível, foi marcado por opressão, perseguições, exclusão e supressão de direitos, culminando com a retomada do antissemitismo aberto da era estalinista. Não obstante, a cooperação do movimento operário judaico com a social-democracia russa, que, apesar de um constante estranhamento com o proletariado russo, em boa parte viabilizou o sucesso da Revolução, acenava para uma plena integração dos judeus; de fato, num primeiro momento os judeus obtiveram plenos direitos civis. Porém, a III Internacional, fundada por Lênin em 1918, instituiu um rígido centralismo sob o comando do PCUS e negou-se a considerar os judeus como uma nacionalidade, não lhes permitindo participar naquela organização e recusando-se até mesmo a admitir a própria existência de uma "Questão Judaica".
\end{abstract}

Palavras-chave: Internacional Comunista. Movimento operário judaico. Social-democracia Russa. Antissemitismo. Questão Judaica.

Abstract: The relationship of Jews with power in Russia in the four centuries since Ivan the Terrible's reign has been marked by oppression, persecution, exclusion and suppression of rights, culminating in the resumption of open anti-Semitism in the Stalinist era. Nevertheless, the cooperation of the Jewish labor movement with the Russian social democracy, which, despite a constant strangeness with the Russian proletariat, largely made the success of the Revolution possible, beckoned for the full integration of the Jews; in fact, at first the Jews obtained full civil rights. However, the III International, founded by Lenin in 1918, instituted a rigid centralism under the command of the CPSU and refused to regard the Jews as a nationality, not allowing them to participate in that organization and even refusing to admit the very existence of a "Jewish Question".

Keywords: Communist International. Jewish Labor Movement. Russian Social Democracy. Anti-Semitism. Jewish Question.

A Internacional Comunista foi também conhecida como III Internacional ou Comintern. Apenas para situar o pano de fundo deste artigo, gostaria de começar citando as palavras com que o próprio Lênin apresentava a organização em um texto datado de 15/04/1919, sob o título "La Tercera Internacional y su lugar en la historia":

A I Internacional (1864-1872) lançou as bases da organização internacional dos trabalhadores para a preparação de sua ofensiva revolucionária contra o capital. A II Internacional (1889-1914) foi uma organização internacional do movimento proletário, cujo crescimento se realizava em amplitude, o que não deixou de influir na redução temporal da altitude do nível revolucionário, no fortalecimento temporal do oportunismo, que, no fim das contas, levaram a dita Internacional a uma bancarrota ignominiosa.

De fato, a III Internacional foi criada em 1918, quando o longo processo da luta contra o oportunismo e o social-chauvinismo, sobretudo durante a guerra, conduziu à formação de partidos comunistas em uma série de nações. Formalmente, foi fundada em seu I Congresso, celebrado em março de 1919, em Moscou. E o traço mais característico desta Internacional, sua missão, é o cumprimento, o levar à prática os preceitos do marxismo e realizar os ideais seculares do socialismo e do movimento operário. Este traço, o mais característico da III Internacional, se revelou imediatamente em que a nova, a terceira "Associação Internacional dos

\footnotetext{
* Pesquisador independente. Doutor em Letras pela Faculdade de Filosofia, Letras e Ciências Humanas da Universidade
} de São Paulo. E-mail: <saul.kirschbaum@gmail.com>. 
Trabalhadores" começou a coincidir, já desde agora, em certo grau, com a União de Repúblicas Socialistas Soviéticas. ${ }^{1}$ (tradução livre da versão em espanhol)

Como veremos, a resolução da chamada "Questão Judaica" não recebeu qualquer tratamento prioritário por parte da Internacional Comunista. Nem muito menos: a organização sequer reconheceu a existência de uma "Questão Judaica". Para refletir de forma adequada sobre esta postura, é necessário, antes de mais nada, contextualizar a evolução do tema - a relação entre os judeus e o poder na Rússia -, desde a época tsarista até a ocorrência da Revolução de Outubro de 1917 e a criação da III Internacional em 1919, "uma relação difícil", como aponta o título de livro de Arlene Clemensha (1998), mas difícil desde muito antes do advento do marxismo.

Marcos Margulies registra que em 1484, na época, portanto, de consolidação de Moscou como centro do império russo em formação, ou seja, antes ainda da instituição do tsarado, o Grão-Príncipe Ivã III tentou, sem êxito, atrair mercadores judeus. No entanto, a presença destes, a partir do reinado de Ivã IV, o Terrível - que esteve no poder de 1533 a 1584 -, foi sempre rejeitada. Cada vez que o império se expandia pela conquista de novos territórios, os judeus eventualmente lá residentes eram imediatamente expulsos, deportados para regiões inóspitas ou simplesmente afogados. Esta obstinação pode, talvez, ser decorrente de um projeto de consolidação do povo russo em torno da Igreja Ortodoxa, que via os judeus como rivais, ameaças à pureza e à santidade da Rússia. ${ }^{2}$

Esta situação, de praticamente inexistência de judeus na Rússia, perduraria até o final do século XVIII. Entre 1772 e 1795, a Rússia, a Áustria e a Prússia procederam, através de três partilhas sucessivas, à eliminação da Polônia do mapa. Ao longo desse processo, aos 36 milhões de habitantes da Rússia uniram-se em poucos anos mais nove milhões de poloneses, ucranianos, lituanos, bielorussos, cossacos. Dez porcento deste total - cerca de 900 mil pessoas - eram constituídos por judeus. Nas palavras de Arlene Clemensha, que aponta para um número de judeus ainda um pouco maior,

[a] Rússia, que desde os tempos de Ivan, o Terrível, proibia expressamente a entrada do judeu, "esse elemento subversivo", "deicida", "explorador dos bons cristãos", viuse repentinamente "inundada" por ele como resultado de sua própria expansão imperialista. A partilha e re-partilha da Polônia entre Rússia, Prússia e Áustria em 1772, 1792 e 1795, seguida pela conquista russa do Ducado de Varsóvia, determinou que a maior parte da antiga Polônia ficasse sob o domínio russo (até 1918) e, com ela, mais de um milhão de judeus, em rápido crescimento demográfico. ${ }^{3}$

Para lidar com essa massa de judeus, impossível de ser simplesmente expulsa ou exterminada, a imperatriz Catarina II, a Grande (1762-1796), que governava o império durante as partilhas da Polônia, transformou a região já habitada por judeus em uma zona de confinamento, a chamada "zona de residência", composta, grosso modo, pela Polônia "do Congresso" (isto é, sob domínio russo) e pelas províncias do noroeste, sudoeste e sul, que compunham respectivamente a Lituânia, a BieloRússia e a Ucrânia ${ }^{4}$.

Este confinamento só veio a ser abolido em 1917, pela revolução de Fevereiro. Segundo Clemensha,

\footnotetext{
${ }^{1}$ LÊNIN, s.d., p. 461.

${ }^{2}$ MARGULIES, 1971, p. 147.

${ }^{3}$ CLEMENSHA, 1998, p, 88.

${ }^{4}$ A "Zona de Residência" é também conhecida como Pale, de sua denominação em inglês, "Pale of Settlement". Segundo Ettinger, a lei que a criou em 1791, proibindo os judeus de deixarem permanentemente as novas províncias recentemente adquiridas, foi consequência dos atritos com os mercadores locais resultantes das tentativas de mercadores judeus de negociar na Rússia central. (ETTINGER, 1997, p. 757).
} 
[a]s alterações feitas pelos sucessores de Catarina na zona de residência foram todas no sentido de restringi-la cada vez mais; excessão feita a Alexandre II, que, numa tentativa de russificação dos judeus mais ricos e bem-instruídos, permitiu que os mercadores prósperos das primeiras guildas e os graduados tomassem residência no interior da Rússia. Quaisquer outros "alargamentos" da zona de residência não passaram de tentativas frustradas de manipulação dos judeus para a colonização de meios rurais inabitados, de difícil acesso e largamente improdutivos em função do clima e terreno adversos. ${ }^{5}$

O persistente e opressivo clima de antissemitismo, que resultava em dificuldades econômicas, restrições à inserção no sistema educacional e pogroms, somado ao confinamento territorial, motivaram uma intensa busca por melhores oportunidades fora do Império Russo ${ }^{6}$. Entre o final do século XIX e o início do século XX, quatro milhões de judeus saíram da Europa oriental sob domínio russo.

Não obstante, um forte crescimento populacional, que superou em muito a perda por emigração, deu origem ao surgimento de um proletariado judaico industrial. Segundo Clemensha, no final do século XIX a população judaica naquela região superava a cifra de cinco milhões, mais de metade da qual encontrava-se condenada a obter seu sustento em ramos menores e marginais da produção industrial. ${ }^{7}$

Note-se que mesmo como operários a trajetória dos judeus era diferente da de seus colegas russos. Ainda conforme Clemensha,

o proletariado russo se recruta entre servos e ex-servos diretamente saídos dos meios rurais e concentrados na grande indústria. O proletariado judeu da "zona de residência" se diferenciava, efetivamente, pelo seu caráter semi-artesanal. Ou seja, "a maioria dos assalariados judeus são artesãos que trabalham para pequenos patrões judeus em oficinas ou na pequena indústria de consumo". ${ }^{8}$

Com mais de metade de sua população ocupada em atividades de trabalho industrial, e face à difusão das ideias da Haskalah ${ }^{9}$ na Europa oriental, era inevitável que surgissem esforços de organização no seio do proletariado judaico. Clemensha observa que "durante a década de 1880, a Haskalah, já tendo servido de ponte, para os filhos da classe média judaica, entre o tradicionalismo religioso e o 'mundo moderno', começa a penetrar nos meios operários". ${ }^{10}$

${ }^{5}$ CLEMENSHA, 1998, p. 88.

${ }^{6}$ A morte de Alexandre II num atentado a bomba, por exemplo, abriu uma era de guerra declarada aos judeus. O tsar foi morto por uma bomba em março de 1881 (pelo calendário juliano então em vigor). O fato de Alexandre II ter sido assassinado por uma bomba revolucionária, e de uma judia ter sido presa por envolvimento na conspiração, forneceram evidência suficiente para lançar a culpa sobre os judeus. Teve início, no domingo de Páscoa de 1881, uma onda de tumultos tolerados pelas autoridades que afetou mais de cem comunidade judaicas. Além de pilhagens, ocorreram também casos de assassinato e estupro. Os pogroms, denominados por escritores judeus como "as tempestades do sul", viriam prover o impulso final para centenas de milhares de judeus russos fugirem de sua terra natal para os Estados Unidos. Curiosamente, em uma circular assinada por seu diretório de emergência, o Narodnaya Volya ("A Vontade do Povo"), a organização populista subterrânea que havia promovido o atentado, aderiu às festividades assassinas, convocando os camponeses a matar igualmente "barões, judeus e oficiais tsaristas". (ETTINGER, 1997, p. 884.)

${ }^{7}$ CLEMENSHA, 1998, p. 94.

${ }^{8}$ CLEMENSHA, 1998, p. 99.

${ }^{9}$ Hebraico, lit. inteligência, ilustração, sabedoria. Iluminismo. Designa o movimento de renovação do judaísmo iniciado na Alemanha, em meados do século XVII, sob a direção de Moses Mendelssohn. Segundo Hannah Arendt , “O Iluminismo prometia aos judeus emancipação e, acima de tudo, provia-os de argumentos para reivindicarem iguais direitos humanos" (ARENDT, 2007, p. 22). (tradução livre).

${ }^{10}$ CLEMENSHA, 1998, p. 108. 
Por outro lado, a respeito da natureza destes esforços, Mishkinsky reporta que

Desde o início, o movimento operário judaico ligou-se à história do socialismo europeu. Sua contínua existência como organização data do fim de 1888, quando da formação da Segunda Internacional no Congresso de Paris em 1889. Mas sua origem recua praticamente à época da dissolução oficial da Primeira Internacional. Em maio de 1876 havia, estabelecida em Londres, a Sociedade Hebraica Socialista (chamavase a si mesma em hebraico Agudat Ha-Sozialistim Ha-Ivrim). Esta foi a primeira associação socialista de operários judeus ${ }^{11}$.

$\mathrm{Na}$ Europa oriental sob domínio russo, o processo de organização começou pela formação de krujki, que significa algo como "núcleos de propaganda". Segundo Clemensha, "a partir de 1895 diversas lideranças do movimento operário judeu já se manifestam favoráveis à unificação dos diferentes núcleos em uma organização mais ampla. Mas esta só se tornaria uma 'tarefa urgente' em 1897'. ${ }^{12}$ Note-se que desde o início o relacionamento dos operários judeus com seus colegas russos e poloneses seria marcado por um estranhamento, apontando para um distanciamento. Conforme essa autora,

[a] reunião efetuada no dia seguinte ao $1^{\circ}$ de Maio (1895) de Vilna (considerada a primeira grande comemoração do tipo na "zona de residência", com a participação de 250 operários judeus e a presença de bandeiras vermelhas com inscrições em iídiche), seria marcada por um pronunciamento de Martov que, segundo Weinstock, continha em germe o nascimento do Bund ${ }^{13}$. Nele, Martov [que viria, no futuro, a ser importante líder menchevique] sublinha a dimensão nacional da opressão dos trabalhadores judeus, que sofriam, como trabalhadores, o jugo do capital, e como judeus, a ausência de direitos cívicos; denuncia igualmente a burguesia judaica, a "pior de todas", que jamais empreenderia uma luta séria por sua própria emancipação; e defende a adoção, pelos social-democratas locais, de uma "política especificamente judia", em vista da possibilidade (bastante concreta, segundo ele) de as classes operárias russa e polonesa sacrificarem os interesses dos trabalhadores judeus em prol de seus interesses próprios. $^{14}$

O Bund (União Geral dos Trabalhadores Judeus na Lituânia, Polônia e Rússia), criado em 1897, preconizava a instauração do sistema socialista, com a manutenção da autonomia cultural de cada grupo nacional, inclusive dos judeus; foi enorme sua importância na evolução dos movimentos revolucionários da Rússia, tendo inclusive exercido papel de relevo na formação do Partido Operário Social-Democrata Russo (POSDR), que só se constituiu em março de 1898 e viria a se transformar, após sua divisão nas facções bolchevique e menchevique, em Partido Comunista da União Soviética (PCUS). Ettinger destaca que "não é coincidência que a primeira conferência do Partido tenha sido sediada em Minsk [atual capital da Bielo-Rússia], cidade da Região de Assentamento na qual o Bund operava, e este tenha colocado à disposição do Partido uma gráfica ilegal"15.

\footnotetext{
${ }^{11}$ MISHKINSKY, 1972, p. 313. Não por coincidência, a Associação foi fundada por um judeu russo, Aaron Samuel Liebermann (1845-1880), que viria a ser conhecido como o "pai do socialismo judaico". Forçado a fugir da Rússia em 1875, Liebermann fundou, com vários outros emigrantes judeus, a Sociedade Hebraica Socialista em Londres, com o objetivo de "disseminar conhecimento do socialismo entre os judeus, onde quer que residam". Em 1877 Liebermann fundou em Viena o primeiro jornal socialista judaico em hebraico, Ha'emet (“A Verdade”) (ETTINGER, 1997, p. 846).

${ }^{12}$ CLEMENSHA, 1998, p. 125.

13 Ídiche: laço, ligação, vínculo, aliança, liga.

${ }^{14}$ CLEMENSHA, 1998, p. 126.

15 ETTINGER, 1997, p. 910.
} 
$\mathrm{Na}$ verdade, o Bund ultrapassou seu papel de organização política; nas palavras de Lucy Dawidowivch,

[f]rom its small illegal beginnings, the Jewish Labor Bund later evolved into a major force in Jewish life, the only modern movement that in the lifetime of East European Jewry successfully competed with Zionism, offering both masses and classes another mode of Jewish identification. The Bund became a channel through which many alienated and assimilated Jews returned to their own people and their own culture. ${ }^{16}$

A disseminação de ideias socialistas entre o proletariado judeu, porém, não se limitou ao Bund. Outras organizações, como o Partido Operário Social-Democrata Judeu Poalei Tsion, o Partido Operário Socialista Judeu e o Partido Operário Sionista Socialista, constituiam as chamadas correntes territorialistas-sionistas, pois, ao contrário do Bund, defendiam o estabelecimento dos judeus em território próprio, não necessariamente na Palestina. A mais importante dessas organizações foi o Poalei Tsion. "A extrema esquerda do sionismo socialista", segundo Avineri, "reagrupada no seio do movimento Poalei Tsion de esquerda, considerava o sionismo socialista como um meio de realizar a revolução proletária no contexto judaico"17.

Outros ainda, os chamados "judeus não-judeus"18, como Trotsky, buscavam solucionar o problema judeu através da modificação radical da estrutura da sociedade em geral, numa revolução que traria em seu bojo o desaparecimento do judaísmo. Este último grupo, apesar de numericamente insignificante em relação à população judia total no Império tsarista, foi extremamente importante para as atividades revolucionárias.

O mais importante agrupamento militante do proletariado judeu, o Bund não se considerava um partido separado, mas sim uma parte da democracia social russa. Porém, suas relações com o Partido Social Democrata russo foram tensas desde o início, uma história de aproximações e afastamentos: no segundo congresso da social democracia russa, no verão de 1903, por exemplo, o Bund exigiu ser reconhecido como "único representante do proletariado judeu"; isto encontrou a oposição da maioria, que rejeitou o princípio federativo na organização partidária. O curioso é que seus principais oponentes nesta questão foram militantes judeus. Dos 45 delegados presentes ao evento, 25 eram judeus (entre os quais Trotsky e Martov), sendo cinco representantes do Bund. Estes números evidenciam, também, a magnitude da participação judaica na social democracia russa. $\mathrm{Ou}$ seja, dos 40 delegados não ligados ao Bund, nada menos que a metade era composta por judeus. Notese ainda que neste congresso - logo antes da cisão entre os dois grupos - os mencheviques apoiaram os bolcheviques contra o Bund. ${ }^{19}$ Em consequência da rejeição da reivindicação, o Bund anunciou sua secessão do partido e, a partir de então, houve crescente atrito com os social-democratas, por causa de suas atividades paralelas no Distrito de Residência.

O IV Congresso do POSDR, que reuniu-se em abril de 1906 em Estocolmo, no entanto, concordou por fim em aprovar o status autônomo do Bund e em abster-se de decidir sobre a questão do programa nacional. Com base nesta decisão, a sétima conferência do Bund, reunida em Leipzig no mesmo ano, decidiu retornar às fileiras do partido.

Esta era a situação até o início de 1917. Com a vitória da Revolução de Fevereiro, porém, o novo governo aboliu as discriminações contra os judeus e lhes outorgou igualdade de direitos. Os

\footnotetext{
${ }^{16}$ DAWIDOWICZ, 1967, p. 59-60: "De seus pequenos e ilegais começos, o Bund evoluiu para uma importante força na vida judaica, o único movimento moderno que no período de existência do judaísmo leste europeu competiu com o sionismo, oferecendo, tanto para as massas quanto para as classes sociais, outro modo de identificação judaica. O Bund tornou-se um canal através do qual muitos judeus alienados e assimilados retornaram para seu próprio povo e para sua própria cultura" (tradução livre).

${ }^{17}$ AVINERI, 1982, p. 276.

${ }^{18}$ Conforme a expressão cunhada por Isaac Deutscher em 1958 (DEUTSCHER, 1970, p. 27).

${ }^{19}$ CLEMENSHA, 1998, p. 132.
} 
partidos judeus, que tinham restringido ou mesmo totalmente suspendido suas atividades durante o período reacionário que começou em 1907, agora despertaram para grande atividade e se tornaram extremamente influentes no mundo judaico.

Segundo Ettinger, as convenções dos partidos judaicos e suas publicações unanimemente exigiam o direito à autonomia nacional, mas enquanto o Bund se contentava com autonomia apenas no campo da educação e cultura, os outros partidos expandiram suas exigências para áreas mais abrangentes, como bem-estar e ajuda econômica mútua, reconhecimento legal das leis matrimoniais judaicas, o direito de observar o shabat, entre outros. Esta situação diferia daquela vigente na virada do século, pois agora os partidos não-judaicos começavam a apoiar a ideia de autonomia judaica nacional e cultural. Em 1917, esta foi a decisão dos Socialistas Revolucionários, dos Mencheviques e dos Democratas Constitucionais. O único partido de esquerda ou de centro contrário a essa reinvindicação era o partido bolchevique, que, a despeito do número considerável de ativistas judeus em suas fileiras e mesmo entre seus líderes, não gozava de qualquer influência real no milieu judaico ${ }^{20}$. Segundo a Encyclopaedia Judaica, "a maioria dos judeus ativos nas fileiras bolcheviques antes de 1917 eram intelectuais assimilacionistas. Poucos trabalhadores judeus na Rússia pertenciam aos bolcheviques" 21 .

Ainda segundo Ettinger, os objetivos iniciais dos partidos judaicos incluiam a restauração da vida comunitária e o estabelecimento de uma representação para toda a Rússia. De fato, durante a segunda metade de 1917 foram realizadas eleições democráticas para os conselhos comunitários e para uma conferência judaica de toda a Rússia. Esperava-se que esta conferência levaria as reivindicações judaicas perante a Assembleia Constituinte de toda a Rússia, eleições para a qual foram realizadas ao mesmo tempo. ${ }^{22}$

A Revolução bolchevista de outubro de 1917 frustrou todos esses planos. A Conferência Judaica não se realizou, e a Assembleia Constituinte russa, em eleições para a qual os Socialistas Revolucionários ganharam uma maioria decisiva, foi dispersada à força pelos bolchevistas imediatamente após sua convocação em 5 de janeiro de 1918. O público judeu não se submeteu: em julho de 1918 representantes da comunidade se reuniram em Moscou e elegeram um bureau central cuja tarefa era coordenar as atividades das instituições judaicas. Mas tanto a federação comunitária quanto os partidos ficaram sujeitos a pressão e perseguição crescentes de parte do regime soviético. O Bund, em seu VIII e último Congresso, realizado em dezembro de 1917, já havia reiterado a posição mantida na última década e meia: repudiou a Revolução de Outubro, negou qualquer apoio ao "golpe bolchevique", e passou a boicotar os órgãos soviéticos para a condução dos assuntos judaicos: a Yevkom (seção judaica do Comissariado para as Questões Nacionais, presidido por Stalin), criada em janeiro de 1918 e dissolvida em abril de 1921; e a Yevsektsia (seção judaica do Partido Comunista), criada em julho de 1918 e dissolvida por ocasião da dissolução de todas as "seções nacionais" entre 1926 e 1928. Por fim, em 1920 o próprio Bund, assim como o partido menchevique, seriam extintos.

Segundo Paul Johnson, o medo que os judeus sentiam dos sovietes era bem fundamentado. Em agosto de 1919 todas as comunidades religiosas judaicas foram dissolvidas, suas propriedades confiscadas, e a esmagadora maioria das sinagogas fechada para sempre. O estudo do hebraico e a publicação de obras seculares em hebraico foram banidos. A impressão em ídiche era permitida, mas somente em transcrição fonética. ${ }^{23}$

E agora, de volta à Internacional. Ou melhor, às Internacionais. Pois é sabido que os judeus estavam representados na II Internacional desde a sua fundação, em 1889. A partir de 1896, essa representação se deu por meio dos partidos operários judaicos mais importantes, que eram os da Rússia. Não obstante, até a dissolução da II Internacional, em 1914, os judeus jamais constituíram

${ }^{20}$ ETTINGER, 1997, p. 964-965.

${ }^{21}$ Encyclopaedia Judaica, 1978, p. 794.

${ }^{22}$ ETTINGER, 1997, p. 965.

23 JOHNSON, 1988, p. 453. 
uma seção nacional própria. Essa representação nacional autônoma tampouco estava nos planos e reinvindicações do principal partido operário judeu, o Bund. ${ }^{24}$

A II Internacional foi questionada em relação à Questão Judaica, mas reagiu de forma evasiva. Mishkinsky reporta que no congresso da entidade em Bruxelas, em 1891, o representante das organizações de "operários de língua ídiche" nos Estados Unidos encaminhou a seguinte pergunta à ordem do dia: "Qual deverá ser a atitude dos trabalhadores organizados em todos os países para [com] a questão judaica?" O estímulo para tal pergunta era a crescente perseguição dos judeus na Rússia e especialmente sua expulsão de Moscou. O congresso resolveu excluir a pergunta da ordem do dia. Não resolveu que era dever dos partidos socialistas lutar contra o antissemitismo ou propor como exigência programática a igualdade de direitos políticos para todos os cidadãos sem consideração de religião ou nacionalidade. Ao invés, o congresso denunciou tanto o "antissemitismo" como o "filossemitismo". E rejeitou enfaticamente as aspirações judaicas de autonomia, com a seguinte declaração: "Os operários de língua ídiche não possuem outros meios de libertação exceto a unidade com os partidos operário-socialistas nos países onde habitam". ${ }^{25}$

Os partidos operários judeus podiam participar da II Internacional graças a seu caráter federativo; as seções não correspondiam necessariamente a Estados ou entidades políticas, mas a nacionalidades; esta participação se dava em conjunto com a delegação do país de origem. Assim, no congresso de Paris, em 1900, do total de 29 membros da delegação russa, 12 pertenciam ao Bund. Porém, o congresso seguinte, em Amsterdã (1904), foi realizado um ano após a ruptura do Bund com o Partido Operário Social-Democrata Russo, dando origem ao problema de sua representação na Internacional.

Com relação à III Internacional, a situação só se agravou, já que esta, como vimos acima, funcionava de forma centralizada, sob o comando do PCUS, e só reconhecia representações de partidos comunistas com base territorial. Os Estatutos da Internacional Comunista, aprovados no II Congresso, que se realizou em julho de 1920, por exemplo, em seu artigo 3, estabelecia que "todos os partidos e organizações afiliadas à Internacional Comunista levam o nome de Partido Comunista de tal ou qual país (seção da Internacional Comunista)" ${ }^{26}$

No mesmo Congresso, foi aprovada uma Resolução sobre o papel do partido comunista na revolução proletária, vedando até mesmo a atuação política local, fora dos marcos do centralismo. Seu item 16 estabelecia que "a reivindicação de uma ampla 'autonomia' para os grupos locais do partido nestes momentos não pode senão debilitar as fileiras do partido comunista, diminuir sua capacidade de ação e favorecer o desenvolvimento das tendências anarquistas e pequeno-burguesas opostas à centralização". ${ }^{27}$

Note-se que a importância da questão das nacionalidades oprimidas e seu potencial revolucionário fora reconhecida de maneira enfática pelo PCUS. Nas palavras de Trotski,

o Partido Bolchevique lutou, durante anos, pelo direito de autodeterminação das nacionalidades, isto é, pelo direito à completa separação estatal. Foi precisamente por causa desta exata posição na questão nacional que o proletariado russo pôde ganhar, pouco a pouco, a confiança das populações oprimidas. ${ }^{28}$

Na verdade, a posição da Internacional resultava da do próprio PCUS, que recusava a filiação dos partidos judaicos em decorrência da adoção de um conceito de "nacionalidade", defendido por Stalin, que não abrangia os judeus. Segundo a Encyclopaedia Judaica,

\footnotetext{
${ }^{24}$ CLEMENSHA, 1998, p. 77-78.

${ }^{25}$ MISHKINSKY, 1972, p. 320.

${ }^{26}$ Estatutos da Internacional Comunista, 2017, p. 57

${ }^{27}$ Estatutos da Internacional Comunista, 2017, p. 75

${ }^{28}$ TROTSKI, 1967, p. 142.
} 
Em um ensaio publicado em 1913 sob o título "A Questão Nacional e a Social Democracia" (mais tarde conhecido sob o título "O Marxismo e a Questão Nacional"), que teve a aprovação de Lênin e era devotado em grande parte aos judeus, Stalin propôs uma definição dogmática do conceito de nacionalidade: "Uma nação é uma comunidade estável de pessoas, historicamente constituída, formada sobre a base de linguagem, território, vida econômica e formação psicológica comuns, manifestada em uma cultura comum". Se apenas uma única dessas características estiver faltando, não há "nação". Com base nesta definição, Stalin argumentava que as comunidades judaicas vivendo nos diversos países não constituiam uma mesma nação. Apesar de que cada uma delas pudesse ser descrita como possuindo um "caráter nacional" comum, elas deviam ser vistas como "tribos" ou "entidades étnicas". [...] Seguia-se que o programa do Bund de "autonomia nacional" referia-se a uma "nação cujo futuro é negado e cuja existência ainda carecia de ser provada". ${ }^{29}$

Segundo a mesma Encyclopaedia Judaica, desde o início o Comintern foi forçado a lidar com a questão de suas relações com o movimento operário judaico, que era ele mesmo uma espécie de internacional em miniatura. O Poalei Tsion tinha sua União Mundial, e o Bund, mesmo carecendo de uma organização mundial própria, exercia grande influência entre as organizações operárias judaicas na Europa e na América. O movimento operário judaico na Rússia pré-revolucionária também tinha exercido influência ideológica sobre trabalhadores judeus em outros países e mesmo sobre grupos judaicos que não pertenciam à classe operária. Mais ainda, o movimento operário judaico tinha vínculos intrincados com organizações operárias gerais e com o movimento operário internacional e tinha em suas fileiras muitos revolucionários experientes. ${ }^{30}$

Porém, os rígidos princípios de estrutura organizacional tornavam impossível qualquer participação judaica organizada na III Internacional. Esforços de grupos do Bund orientados ao comunismo (o Kombund) para juntar-se ao Comintern como uma organização terminaram em fracasso, como aconteceu também com tentativas similares do Bund polonês. Em 1920, após prolongadas negociações, o Comintern rejeitou uma proposta para a criação de uma seção judaica, que agruparia todos os corpos comunistas ativos no proletariado judaico (a Yevsektsiya, o Kombund e o Poalei Tsion comunista). Outra proposta, apresentada ao segundo congresso do Comintern, pela qual a União Internacional de Poalei Tsion seria aceita como membro, enquanto suas ramificações teriam permissão para formar seções judaicas dos respectivos partidos comunistas e reteriam algum grau de autonomia em assuntos relativos a necessidades específicas das massas judaicas, também foi rejeitada.

Em nível individual, não obstante, a III Internacional recebeu representantes dos partidos judaicos. Como informa Isaias Golgher em nota de rodapé,

[d]entro do Bund formou-se uma ala que tendia para a adesão à Terceira Internacional. O mesmo ocorreu dentro do Poalei-Sion. Este movimento surgiu quando ambos foram convidados como "delegados fraternais" ao Terceiro Congresso do Comintern, que se realizou em agosto de 1921. Os elementos pró-comunistas acabaram por abandonar seus partidos e ingressaram nas fileiras do ievsequismo. ${ }^{31}$

\footnotetext{
${ }^{29}$ Encyclopaedia Judaica, 1978, p. 797.

${ }^{30}$ Encyclopaedia Judaica, 1978, p. 802.

${ }^{31}$ GOLGHER, s.d., p. 38.
} 
Em 1921 o conselho executivo da Internacional anunciou a formação de um Bureau de Assuntos Judaicos para dirigir a propaganda entre trabalhadores judeus em todo o mundo; porém, nada mais se soube da realização desse plano.

Enfim, a nota dominante no âmbito da III Internacional em relação à Questão Judaica é o silêncio. Consultando a publicação Los cuatro primeros congresos da la Internacional Comunista ${ }^{32}$ verifica-se a absoluta ausência de qualquer referência àquela questão. Como afirma a Encyclopaedia Judaica, o Comintern "não teve nada a ver com problemas judaicos ao longo do período de sua existência". ${ }^{33}$

Em teoria, o Comintern não reconhecia nem um povo judeu mundial nem a existência de um problema judaico mundial; concedia que um problema como esse poderia existir em certos países, caso em que sua resolução seria de responsabilidade da seção local da Internacional. Raramente havia qualquer menção a antissemitismo nos congressos, nas sessões plenárias do Comitê Executivo e em sua imprensa.

Esta postura do Comintern, porém, baseada, como vimos, no conceito de nacionalidade imposto por Stalin, não impediu o PCUS de alocar um território dentro da União Soviética para o estabelecimento de uma república judaica. O curioso é que o próprio decreto de criação mencionou o "povo judeu". Nas palavras de Golgher,

O dia 28 de março [de 1928] passou a ser, por muitos anos, um dia histórico para os comunistas judeus. Nesse dia, o governo soviético designou a região às margens do Rio Amur, na Sibéria, fazendo limite com a Mandchúria, para ser colonizado por judeus. Em 1934, o distrito foi proclamado como Região Autônoma Judaica, que seria a futura República Socialista Soviética Judaica de Birobidjan.

O decreto que a instituiu dizia:

"Pela primeira vez na História do povo judeu, está se realizando o seu ardente desejo de formar sua Pátria, seu próprio Estado Nacional”. (grifo no original) ${ }^{34}$

Note-se que em 1928 o Secretário Geral do PCUS já era Stalin. Lênin havia morrido em 21/01/1924. A par dos aspectos positivos e negativos, a iniciativa pode ser vista como uma tentativa de esvaziar os partidos judaicos sionistas-territorialistas, especialmente o Poalei Tsion. Afinal, se já existe um estado judeu, a proposta de um assentamento na Palestina perde substância.

De fato, o Comintern não deixou de se posicionar em relação ao Sionismo e ao estabelecimento judaico na Palestina. O segundo congresso, realizado em 1920, denunciou o sionismo, o qual, "por sua reinvindicação de um estado judaico na Palestina, onde trabalhadores judeus formam apenas uma pequena minoria, na realidade entrega os trabalhadores árabes para exploração pela Inglaterra". ${ }^{35}$

Finalmente, a própria Internacional Comunista foi extinta por Stalin em 1943. Passados 100 anos, porém, a reflexão sobre a Terceira Internacional e sua postura em relação à Questão Judaica continua atual e relevante, objeto de um sem-número de pesquisas, como se pode verificar acessando o site https://scholar.google.com/ e procurando por "The Communist International and the Jewish Question"36.

\footnotetext{
${ }^{32}$ Ou seja, todos de que Lênin participou. Quando da realização do V Congresso, presidido por Stalin, Lênin já havia morrido.

${ }^{33}$ Encyclopaedia Judaica, 1978, p. 801.

${ }^{34}$ GOLGHER, s.d., p. 44.

${ }^{35}$ Encyclopaedia Judaica, 1972, p. 802; Los cuatro primeros congresos de la Internacional Comunista. 2017 , p.83.

${ }^{36}$ Acesso em 21/11/2019.
} 


\section{Referências}

ARENDT, Hannah. Original assimilation: an epilogue to the one hundredth anniversary of Rahel Varnhagen's death. In The Jewish Writings. New York: Schocken Books, 2007. p. 22-28. AVINERI, Shlomo. Histoire de la Pensée Sioniste: les origines intellectuelles de l'État Juif. (trad. Erwin Spatz). Paris: Éditions Jean-Claude Lattès, 1982.

CLEMENSHA, Arlene. Marxismo e Judaísmo: história de uma relação difícil. São Paulo: Boitempo, 1998.

DAWIDOWICZ, Lucy. Introduction. In: (org). The Golden Tradition: Jewish Life and Thought in Eastern Europe. $3^{\text {rd }}$ edition. Boston: Beacon Press, 1968, p. 5-90).

DEUTSCHER, Isaac. O judeu não-judeu e outros ensaios. (trad. Moniz Bandeira). Rio de Janeiro: Editora Civilização Brasileira, 1970.

ETTINGER, Shmuel. The Modern Period. In: BEN-SASSON, Haim H. (org.). A History of the Jewish People. (trad. George Widenfeld and Nicolson Ltd). Cambridge: Harvard University Press, 1997. p. 727-1096.

GOLGHER, Isaias. A tragédia do comunismo judeu: a história da Ievsektzia. Belo Horizonte: Editora Mineira, s.d.

JOHNSON, Paul. A History of the Jews. New York: Harper Perennial, 1988.

LENIN, Vladimir Ilitch. Marx-Engels-Marxismo. Moscou: Editorial Progreso, s.d.

MARGULIES, Marcos. Os judeus na história da Rússia. Rio de Janeiro: Bloch Editores, 1971.

MISHKINSKY, Moshe. O Movimento Operário e o Socialismo Europeu. In: UNESCO. Vida e Valores do Povo Judeu. São Paulo: Perspectiva, 1972. p. 313-326.

TROTSKI, Leon. O que foi a Revolução de Outubro? (trad. Moniz Bandeira). Revista Civilização Brasileira, Rio de Janeiro, Ano III, Caderno especial 1, p. 133- 155. 1967.

Encyclopaedia Judaica. Jerusalem: Keter Publishing House Jerusalem Ltd, 1978.

Tesis, manifiestos y resoluciones adoptados por los cuatro primeros congresos de la Internacional Comunista (1929-1923). Valencia: Edicions Internacionals Sedov, 2017. Disponível em: <www.grupgerminal.org>. Acesso em 20/11/2019. 